\title{
Metas parentais de socialização da emoção e modelos de self: uma articulação conceitual
}

\section{Parental socialization goals of emotion and models of self: a conceptual articulation}

\section{Metas parentales de socialización de emoción y modelos del self: una articulación conceptual}

\section{Deise Maria Leal Fernandes Mendes*}

Universidade do Estado do Rio de Janeiro - UERJ, Rio de Janeiro, Brasil

\author{
Luciana Fontes Pessôa** \\ Pontifícia Universidade Católica do Rio de Janeiro - PUC-Rio, Rio de Janeiro, Brasil
}

Lilia I êda Chaves Cavalcante***

Universidade Federal do Pará - UFPA, Belém, Pará, Brasil

\begin{abstract}
RESUMO
Este artigo discute a necessidade de articulação entre os conceitos de metas parentais de socialização da emoção e os modelos de desenvolvimento do self, ressaltando-se a importância teórica disto. Para tanto, argumenta que o estudo das metas de socialização remete, forçosamente, à investigação daquilo que os pais almejam para os filhos, especialmente em termos de experiências emocionais e do desenvolvimento de um self mais autônomo, mais interdependente ou relacional, ou autônomo-relacional. O tema, com o foco aqui proposto, tem sido pouco explorado pela literatura PSI, posto que são escassos os estudos que se dedicaram a investigar tal associação. 0 objetivo deste estudo foi o de propor uma reflexão, a partir de algumas referências teóricas e empíricas, as quais serviram de subsídios para um debate sobre metas parentais e seu impacto no desenvolvimento emocional e do self, de maneira articulada. A partir dessa discussão, espera-se salientar a relevância de uma nova linha de pesquisa na área da psicologia do desenvolvimento que abarque essa temática, na perspectiva de integração desses conceitos, antes assimilados de forma desarticulada.
\end{abstract}

Palavras-chave: metas, desenvolvimento, socialização, self, autonomia.

\section{ABSTRACT}

This article discusses the importance of the articulation between the concepts of parental emotion oriented goals and the models of development of self. To this end, we argue that the study of socialization goals necessarily refers to the investigation of what parents wish for their children in terms of their emotional experiences and the development of a more autonomous, related or related autonomous self. This approach, with the focus proposed, has not been commonly used in the scientific literature, given that there are not many studies dedicated to explore this association.

\begin{tabular}{|l|l|l|l|l|l|}
\hline Estudos e Pesquisas em Psicologia & Rio de Janeiro & v. 16 & n. 2 & p. 450-468 & 2016 \\
\hline
\end{tabular}


Thinking about it, in this paper we propose a debate about the impact of parental goals on the children's emotional and self development, aiming to articulate these concepts. From this discussion, we expect to highlight the relevance of a new line of research in the field of developmental psychology to integrate these concepts that are usually unarticulated on the literature.

Keywords: goals, development, socialization, self, autonomy.

\section{RESUMEN}

En este artículo se discute la necesidad de articulación entre los conceptos de metas parentales de la socialización de la emoción y modelos de desarrollo del self, y la importancia teórica de esto. Por lo tanto, argumenta que el estudio de las metas de socialización necesariamente se refiere a la investigación de lo que los padres anhelan para sus hijos en términos de experiencias emocionales y del desarrollo de un self más autónomo e interdependiente o relacional, o autónomo-relacional. El tema, con el enfoque propuesto aquí, ha sido poco explorado en la literatura científica, ya que hay pocos estudios que se han dedicado a investigar esta asociación. Así, el objetivo de este estudio fue proponer una reflexión de algunos referentes teóricos y empíricos que sirvieron de subsidios para un debate sobre los objetivos de los padres y su impacto en el desarrollo emocional y del self, de manera articulada. A partir de esta discusión, se espera enfatizar la importancia de una nueva línea de investigación en psicología del desarrollo, que incluya este tema con la perspectiva de la integración de estos conceptos, antes asimilados de manera desarticulada.

Palabras clave: metas, desarrollo, socialización, self, autonomía.

\section{I ntrodução}

O impacto das metas de socialização, crenças e práticas parentais, relativas às emoções no desenvolvimento dos filhos, tem sido tema de estudos teóricos e empíricos nas últimas décadas (Ayoub, Bartlett, \& Swartz, 2014; Bailey, Denham, \& Curby, 2013; Brownell, Svetlova, Anderson, Nichols, \& Drummond, 2013; Dunsmore, Her, Halberstadt, \& Perez-Rivera, 2009; Malti, Eisenberg, Kim, \& Buchmann, 2013; McElwain et al., 2007). O conjunto de evidências e discussões, que essas investigações suscitam, sinaliza que as emoções são vitais para os cuidados parentais efetivos, como afirma Dix (1991). Contudo, o papel que pais e mães atribuem às emoções em suas vidas e na de seus filhos, bem como nas metas e crenças parentais que orientam suas práticas de cuidado, ainda é pouco conhecido.

A literatura PSI tem apresentado também estudos voltados para o impacto de diferentes modelos culturais e das metas de socialização decorrentes daí, nos processos de construção do self de crianças (Keller et al., 2006; Schröder et al., 2013; Vieira et al., 2010). Três modelos básicos de self foram definidos por Keller (2007) e Kagitçibasi (2007): autônomo (ou individualista), interdependente (ou sociocêntrico) e autônomo-relacionado. Cada modelo é identificado como característico de certos grupos sociais ou 
sociedades, embora seja também esperada variação interna ao grupo (Keller et al., 2006).

Tanto a produção, com foco nas metas parentais de socialização, relativas à autonomia e à interdependência: duas necessidades humanas reconhecidas como presentes, em alguma medida, em qualquer cultura; quanto a voltada para os processos de socialização da emoção, são vastas.

Contudo, o que nos parece constituir uma lacuna grave é a carência de estudos que levem em conta a imbricação dessas duas linhas de investigação. Sendo assim, acreditamos fazer diferença quando pensamos em crenças e práticas parentais e expectativas de desenvolvimento, ligadas a capacidades emocionais na criança, à luz do quanto é também esperado que ela seja mais (ou menos) autônoma, ou tenda mais (ou menos) para os relacionamentos interpessoais e laços familiares. Nosso propósito neste artigo não é o de apresentar uma revisão da literatura pertinente nos referidos campos de estudo, mas o de promover uma reflexão acerca da necessidade desses conceitos serem pensados de modo articulado e, com isso, argumentar a importância de uma linha de investigação com essa preocupação.

Pretende-se discutir a importância de se conhecer melhor o que pensam pais e mães quanto às emoções e ao desenvolvimento emocional em crianças e suas metas de socialização da emoção para os filhos, mas como fenômenos que não são independentes de outros aspectos da parentalidade. Este conhecimento precisa avançar levando em conta também a articulação com o estudo das tendências parentais à valorização da autonomia e/ou da interdependência no processo de construção do self de filhos. Nesse sentido, alicerçados nas bases teóricas e evidências empíricas de sustentação de cada uma dessas temáticas, admite-se como profícuo e imprescindível o empreendimento de investigações com esse foco integrador.

\section{Metas de socialização da emoção e desenvolvimento na infância}

As emoções são recursos dos mais poderosos que os seres humanos detêm para lidar com suas motivações, situações vivenciadas e com a comunicação interpessoal. São fundamentais para que as crianças possam entender a si mesmas e aos outros no mundo social em que vivem, mesmo antes da aquisição da linguagem. Englobando alguns componentes, como as expressões emocionais e a regulação de emoções que são centrais nas interações sociais, ocupando um lugar de evidente importância nas trajetórias de desenvolvimento.

O estudo das emoções tem sido campo para diversos objetos de investigação e severas controvérsias, até mesmo no que diz respeito 
à natureza e origem desses fenômenos. A par de algum consenso quanto a serem as emoções mecanismos de interação complexa com o ambiente e incluírem mudanças fisiológicas, visões distintas demarcam as fronteiras de perspectivas diferenciadas (Holodynski \& Friedlmeier, 2010). É o caso dos embates sobre sua universalidade versus especificidade cultural. Muitos psicólogos assumem a existência de uma base biológica para as emoções humanas e as consideram universais, adaptativas e fruto da história filogenética da nossa espécie (Ekman, 1999; Izard, 1977). Outros adotam uma concepção relativista e culturalista extremada pela qual as emoções são vistas como dependentes da linguagem e decorrentes essencialmente de uma produção cultural (Harré, 1987; Russell, 1991; Nelson \& Russell, 2013).

Neste estudo, tomando por base uma perspectiva sociocultural e evolucionista, que defende a existência dos universais, mas considera a diversidade cultural, assume-se que o desenvolvimento emocional pode ser melhor entendido em termos da interação entre predisposições inatas, comuns às culturas, e o ambiente que estimula o desenvolvimento de padrões específicos da comunidade (Seidl-deMoura \& Mendes, 2012). Assim sendo, a partir de predisposições com que já nascemos, constituem-se diferentes trajetórias de desenvolvimento em função dos processos de socialização estabelecidos.

Como argumenta Keller (2007), as estratégias de socialização adotadas incorporam sistemas de significação cultural que representam o conhecimento acumulado por gerações no ambiente social em que ocorrem. Em todos os grupos culturais, segundo essa autora, os pais desejam passar adiante estratégias que promovam a sobrevivência de suas crianças e sua competência cultural. Essas estratégias são forças vivas que, como tal, estão sujeitas a transformações com o tempo, e se referem a diferentes domínios, incluindo o emocional. O contexto sociocultural compõe o significado e a expressão das emoções (Kitayama, Mesquita, \& Karasawa, 2006; Mesquita, 2007), estabelecendo suas regras de exibição (Ekman, 2003) e as variadas formas de interpretar essas manifestações (Camras, Chen, Bakeman, Norris, \& Cain, 2006; Keller \& Otto, 2009). A experiência emocional e o conhecimento acerca das emoções são constituídos no contexto em que a criança se desenvolve, devendo-se incluir as características das interações no âmbito familiar e demais grupos sociais de que faça parte, e do meio cultural especifico. Como agentes primários de socialização, os pais ensinam as crianças como expressar suas emoções e percebê-las nas outras pessoas, enquanto a cultura fornece orientações sobre como criar filhos e padrões gerais de decodificação e exibição emocional. Assim, conclui-se que as práticas de socialização da emoção podem ser, além de variadas em 
função da cultura, idiossincráticas e não facilmente articuladas pelos pais ou pela criança (Dunsmore et al., 2009).

Examinar as metas e expectativas parentais sobre emoções pode prover um caminho importante para que se conheça o ambiente familiar de socialização que influencia o desenvolvimento das capacidades da criança para reconhecer, expressar, e lidar com as emoções. A ideia é que sejam investigadas as metas que os pais têm quanto ao desenvolvimento emocional que almejam para seus filhos, assim como o que pensam a respeito das emoções e da necessidade de transmitirem conhecimentos às crianças sobre como elas podem manifestar e lidar com suas emoções.

Sabe-se, hoje, que as possibilidades de aplicação desse conhecimento emocional são muitas. Do ponto de vista do desenvolvimento humano, a competência emocional é vital para o sucesso social e acadêmico da criança (Izard et al., 2001), assim como para seu bemestar a médio e longo prazos, e para sua saúde mental (Fine, Izard, \& Trentacosta, 2006). É ainda determinante de sucesso nas relações que estabelece com os adultos (pais e professores, dentre outros) e com seus colegas (Denham, Caal, Bassett, Benga, \& Geangu, 2004).

Estudos sobre processos de socialização da emoção têm procurado mostrar que lugar as emoções ocupam na vida de pais e mães e qual a importância que tais experiências têm no amadurecimento psicológico de seus filhos (Dunsmore et al., 2009). Além disso, recuperam as ideias dos pais e outros cuidadores primários em relação ao que as crianças devem saber e aprender sobre emoções em diferentes momentos da ontogênese (Mendes \& Cavalcante, 2014). Interessam-se ainda em compreender como os pais lidam com suas próprias emoções e de que modo reagem às dos filhos (Meyer, Raikes, Virmani, Waters, \& Thompson, 2014).

Modelos conceituais voltados para a compreensão do processo de socialização emocional destacam o quanto valores e ideias parentais sobre as emoções afetam suas metas em relação aos filhos e as escolhas de práticas e estratégias de socialização de emoção (Dix, 1991; Eisenberg, Spinrad, \& Cumberland, 1998). Deve-se ter em mente, no entanto, que o processo de socialização é bidirecional, e assim como as práticas parentais têm efeito na competência social e emocional das crianças, as reações e comportamentos dos filhos provavelmente se repercutem na forma como seus pais agem e os orientam.

Pesquisas com pré-escolares cujos pais valorizam os ensinamentos sobre emoções passados às crianças, mostram que estes têm filhos com maior conhecimento acerca desse constructo. Mais especificamente, a tendência dos pais em atuar como orientadores e a transmitir conhecimento sobre emoções a seus filhos está associada à maior habilidade destes nas relações com seus pares e melhor 
capacidade em compreender e falar sobre emoções (Bailey et al., 2013; Denham \& Kochanoff, 2002).

Cheah e Chirkov (2008) entrevistaram mães canadenses de préescolares sobre algumas metas de socialização que incluíam, dentre outros aspectos, o ajustamento emocional, disposições emocionais positivas, e autorregulação emocional. Entre as participantes, cerca da metade era aborígene (e se identificavam como índias norteamericanas, Inuit ou Métis) e as demais eram descendentes de povos europeus. Foram encontradas algumas semelhanças no que as mães valorizavam para o desenvolvimento socioemocional das crianças, mas também diferenças entre os dois grupos, de acordo com os valores culturais e ideologias que eram significativos para cada cultura.

Como parte dos resultados divulgados por Cheah e Chirkov (2008), viu-se que as mães de descendência europeia seguiram um modelo cultural individualista em que o ajustamento emocional dos filhos era uma meta porque beneficiava seu autodesenvolvimento. Ainda, segundo esse modelo, o desenvolvimento cognitivo e educacional das crianças Ihes trazia sucesso na vida. No entanto, elas também concordaram com a ideia de que cooperação e sensibilidade social eram desejáveis porque mantinham a harmonia interpessoal. Por seu turno, as mães aborígenes estabeleceram metas de educação infantil como ajustamento emocional, educação e saúde, endossando prescrições culturais em que o equilíbrio emocional e fortes habilidades cognitivas necessárias para a educação e saúde eram importantes para promover o sucesso das crianças. Ao mesmo tempo, valorizaram as habilidades sociais como meio de manter a harmonia interpessoal. Em outros aspectos, as diferenças entre os grupos foram mais marcantes, e, por isso, o estudo destacou a importância das questões socioculturais contemporâneas na investigação da socialização de crianças.

As crenças parentais e relatos de comportamentos ligados à emocionalidade negativa dos pais foram investigados também por Wong, Diener e Isabella (2008), que avaliaram associações entre essas variáveis e a competência de crianças americanas (da 1aa $3^{3}$ e e 5 a séries) em lidar com seus pares. Observaram que altos níveis de encorajamento da expressão emocional negativa e níveis moderados desse tipo de expressão na família relacionavam-se à maior competência das crianças para lidar com seus pares. As crianças de 5 a série com mães que foram mais receptivas à sua expressão de emoções negativas relataram maior competência com pares do que crianças da mesma série escolar cujas mães foram menos receptivas. No estudo de Camras et al. (2006), comparações foram feitas entre grupos de meninas de três anos de idade. As meninas se enquadravam em uma de quatro situações que eram: chinesas residentes na China, chinesas adotadas por americanos de origem 
europeia, americanas de origem chinesa, ou americanas de origem europeia. Como parte dos resultados, verificou-se que as crianças americanas de origem europeia foram mais emocionalmente expressivas do que as americanas de origem chinesa e do que as chinesas que viviam na China. As meninas chinesas adotadas tiveram sua expressividade emocional situada entre as americanas de origem europeia e as demais, mas diferiram significativamente, tanto das que viviam na China, quanto das americanas de origem chinesa para expressões faciais negativas, como as associadas à aversão ou nojo. Autorrelatos de rigor materno, irritação, expressividade e identificação cultural correlacionaram-se com respostas de expressão facial nas filhas.

Para Camras et al. (2006), tais resultados indicaram que o ambiente familiar, ancorado na cultura, pode afetar de forma intensa a expressividade facial nas crianças, originando diferenças entre as de mesma etnia. Por ambiente familiar, podem-se entender componentes que envolvem as metas e práticas de pais e mães quanto ao modo de lidar com as emoções e, portanto, de transmitir isso a seus filhos.

Evidências como as trazidas por esses estudos indicam que algumas características e tendências próprias da psicologia dos cuidadores, como a expressividade emocional dos pais e as ideias que mantêm a respeito das emoções e sua manifestação, podem afetar a produção de expressões emocionais pela criança e a forma como reage às emoções de outras pessoas. Assim como as variações culturais na expressão emocional, as diferenças individuais podem ser pensadas como decorrentes de processos de socialização.

No curso desses processos estão em jogo, além de práticas, as metas de socialização dos pais, que expressam expectativas e objetivos relacionados ao desenvolvimento de seus filhos. O sistema de crenças, metas e práticas parentais certamente não tem como foco único a vida afetiva e emocional da criança, voltando-se também para uma questão central no desenvolvimento do self que é a da valorização da autonomia e proximidade interpessoal. Desse modo, os pais podem almejar que os filhos se tornem indivíduos mais autônomos e voltados para desejos e realizações pessoais e individualizadas, ou mais interdependentes, priorizando relações sociais e familiares harmoniosas. A valorização da autonomia e/ou da relação, como metas parentais, tem sido investigada e discutida por estudiosos nas últimas décadas (Kagitçibasi, 2012; Keller, 2012; Seidl-de-Moura et al., 2009; Vieira et al., 2010). 


\section{A construção e o desenvolvimento do self e as necessidades de autonomia e relação}

Autores têm proposto que as trajetórias de desenvolvimento podem ser estudadas na sua relação com diferentes modelos culturais, que incluem tanto sistemas de crenças, quanto características ecológicas diferenciadas (Keller \& Greenfield, 2000). Fazem parte destes modelos, tendências à valorização de autonomia e interdependência (ou relação) consideradas necessidades universais, desenvolvidas na ontogênese, segundo os processos de socialização e os sistemas de cuidado parentais (Kagitçibasi, 2007; Keller, 2007).

Nesta perspectiva, o desenvolvimento de um bebê humano, em função de certa imaturidade fisiológica e necessidades de cuidado para a sobrevivência, está vinculado à presença de um cuidador e aos sistemas de cuidado parentais estabelecidos, principalmente nos primeiros anos de vida. De acordo com Keller e Chasiotis (2007), o tipo de investimento realizado pelos cuidadores estaria relacionado com as trajetórias de desenvolvimento que eles valorizam. Essas trajetórias podem ser mais voltadas para interdependência, que se caracteriza por perceber o indivíduo principalmente como membro de um sistema social, ou objetivam a independência, com valorização do individualismo, da autonomia, da autorrealização e da autossuficiência (Keller, 2007). Além dessas duas orientações, Kagitçibasi (2007) propôs outra possibilidade, orientada para o desenvolvimento de um self autônomo-relacionado, que envolve características dos dois modelos, constituindo um terceiro, também assumido por Keller (2012).

Para aprofundar a compreensão do desenvolvimento do self é fundamental que sejam considerados esses aspectos da parentalidade associados à influência da cultura e do contexto social em que se dá esse processo. De acordo com Keller (2012), as diferenças entre culturas em termos de cuidados parentais são substanciais e impactantes na construção do self, em suas dimensões de autonomia e interdependência.

Pressupõe-se que estas dimensões começam a ser elaboradas na infância, a partir do contexto em que somos gestados, nascemos e estamos inseridos. Dependendo deste contexto, autonomia e interdependência ganharão importância diferenciada, mas sempre coexistirão já que os indivíduos as apresentam como necessidades humanas (Keller, 2012). Para a autora, as experiências sociais iniciais organizadas por crenças e práticas dos cuidadores, tanto individuais como compartilhadas com o grupo, constituem as bases dessas trajetórias distintas.

Keller (2012), investigando as possíveis trajetórias de desenvolvimento do self, identificou três diferentes contextos em suas pesquisas: um basicamente agrário, com economia de 
subsistência e com baixos níveis de educação formal; um urbano, tipicamente ocidental, pós-industrializado e com altos níveis de educação formal; e outro que seria uma mistura dos anteriores, que pode ser representado pelas famílias não ocidentais de classe média, que possuem altos níveis de educação (similares às famílias urbanas), mas vivem em unidades familiares maiores (similares às famílias agrárias). A partir da análise desses contextos, pode-se identificar a presença de autonomia e interdependência em diferentes níveis, dependendo do papel que assumem em cada contexto.

No primeiro contexto observado por Keller (2012), há a presença de uma cooperação incondicional e inquestionável que é enfatizada por uma estratégia de socialização mais interdependente. As crianças são ensinadas desde pequenas a terem responsabilidades sociais e as atividades motoras e verbais são guiadas para ações sociais. Os pais são responsáveis por acelerar o desenvolvimento motor das crianças para que estas se tornem aptas a ajudar os membros da família. No segundo contexto, a autora demonstra como e porque a independência é priorizada em um ambiente que valoriza e exige a competição. As famílias adotam estratégias de socialização que enfatizam a autonomia. As habilidades cognitivas da criança e o seu desenvolvimento cognitivo são privilegiados, estimulando-os através de atividades diversas e do uso de livros, brinquedos, e outros artefatos voltados para esse fim. Já no terceiro contexto, Keller (2012) observou as raízes da família em um contexto rural, mas com níveis educacionais considerados altos para os padrões de uma área rural. Este alto grau de escolarização seria responsável hoje por diminuir o papel da família como instituição educacional. Embora as crianças continuem participando de atividades no contexto familiar, há uma ênfase tanto na interdependência quando na autonomia, configurando uma trajetória que pode ser descrita como autônomorelacionada, como explica a autora.

A partir dessas diferentes trajetórias, o desenvolvimento do self orienta-se para direções diversas, podendo ser definido como independente, interdependente ou autônomo-relacionado, derivado dos modelos diferenciados de cuidado de pais frente a seus filhos. No caso de selves autônomos ou independentes, tende a ser privilegiada a independência em relação ao grupo social, compreendendo autonomia e separação, caracterizando um tipo de relacionamento distal, marcadamente de famílias de classe média, urbanas e educadas do Ocidente. O segundo modelo, interdependente, privilegia a heteronomia e a relação, caracterizando um tipo de relacionamento proximal, próprio de famílias rurais com baixos níveis socioeconômicos e educacionais. No terceiro, considerado autônomorelacionado, são priorizadas tanto a autonomia quanto a relação.

Nas últimas décadas, e com o decorrer dos anos, várias mudanças na dinâmica das relações interpessoais em diversos contextos puderam 
ser observadas. Um dos principais agentes nesta transformação é o processo de urbanização, que se observa em várias localidades do mundo, e que altera significativamente os estilos de vida da população. O que era adaptativo em um contexto rural, por exemplo, pode não o ser em uma comunidade semiurbanizada, ou que passou por um processo recente de imigração. É o que parece ter ocorrido neste tipo de contexto, com a mudança de uma tendência à interdependência para a valorização da autonomia como forma de se alcançar sucesso social e econômico.

Segundo Kagitçibasi (2012), a urbanização mundial e a imigração têm consequências significativas para a teoria psicológica e, em suas argumentações teóricas, busca descrever como estes fatores socioculturais podem ter repercussões no desenvolvimento humano. Esta autora aponta que os conceitos de autonomia e interdependência têm sido vistos como conflitantes, quando, na verdade, não seria lógico entendê-los deste modo. A presença de um não significa a ausência do outro e, segundo ela, a importância e ênfase que tem sido dada à autonomia em algumas sociedades faz com que a interdependência, muitas das vezes, seja negligenciada. Sua concepção de uma trajetória de desenvolvimento ideal para os tempos atuais indica que "o modelo de um self equilibrado derivado da síntese integrada de autonomia e relação não só é mais saudável psicologicamente por satisfazer necessidades básicas, mas é mais adaptativo em relação ao desenvolvimento socioeconômico, urbanização e industrialização" (p. 2).

Seidl-de-Moura, Carvalho e Vieira (2013) focalizaram o modelo de autonomia-relacionada a partir de uma revisão da literatura PSI representada por estudos brasileiros. Os autores encontraram em estudos realizados nos dezesseis contextos pesquisados em distintas regiões do país evidências de trajetórias de socialização favorecendo tanto a autonomia quanto a relação. Diferentes metodologias (observações mãe-bebê em ambiente natural, análise de conteúdo de falas maternas dirigidas ao bebê, aplicação de escalas de autonomia e interdependência) foram utilizadas e verificou-se que, em geral, se configure uma valorização de ambas as dimensões, alguma variação na tendência estabelecida por cada uma delas estaria relacionada às características sociodemográficas das amostras (variados níveis de urbanização, diversas influências culturais predominantes e diferentes níveis de educação formal).

Em um estudo com um grupo de mães brasileiras do Rio de Janeiro, Seidl-de-Moura et al. (2009) descreveram aspectos dos modelos culturais de 200 mães primíparas com filhos de menos de 44 meses de idade. Os resultados confirmaram a tendência observada com amostras de todas as regiões, e mostraram que as mães do Rio de Janeiro compartilham um modelo de autonomia para seus filhos, mas também acreditam na importância da relação com o outro. Este 
modelo inclui ainda uma preocupação com a estimulação do potencial das crianças em diversas áreas e a forma como seus filhos são apresentados em público. Em geral, esse grupo de mães do Rio de Janeiro declarou desejar sucesso para seus filhos, especialmente em seus aspectos profissional e econômico, mas ressaltam que isso não deveria ser a qualquer preço, e sim através de trabalho duro e com honestidade.

Também envolvendo mães residentes no Rio de Janeiro, um estudo longitudinal realizado por Mendes e Seidl-de-Moura (2013) investigou a valorização de autonomia e relação a partir da análise do conteúdo do discurso materno dirigido ao bebê, que, entre os sistemas parentais de cuidado propostos por Keller (2007), corresponde ao envelope narrativo. Duas duplas formadas por mãe-bebê foram observadas em suas respectivas residências, desde a terceira semana de vida da criança até que ela completasse seis meses. O conteúdo das falas das mães dirigidas a seus bebês foi transcrito e analisado segundo categorias pré-estabelecidas. Esse esforço de categorização se deu no sentido de destacar conteúdos indicativos do seu alinhamento à trajetória de autonomia e de relação. As evidências encontradas nas entrevistas com essas mães mostraram haver uma tendência de valorização da autonomia como meta geral do desenvolvimento, assim como do modelo relacional.

Para Keller (2002), a partir das interações iniciais, e em função da predominância de sistemas parentais específicos e de mecanismos interacionais, a aprendizagem, que se baseia em programas genéticos abertos, leva a experiências que conduzirão a uma concepção modal do self. Essa concepção equilibra as relações entre as seguintes dimensões psicológicas: segurança ("self seguro"), identificada no sistema de cuidados primários e nas respostas contingentes ao bebê nas situações de estresse; relação ("self social"), baseada no sistema de contato corporal e no calor emocional que a criança tem oportunidade de vivenciar; consciência corporal ("self corporal"), ligada ao sistema de estimulação corporal e à individualidade a ele relacionada; individualidade ("self mental"), relacionada aos sistemas de estimulação por objetos e comunicação face-a-face, com respostas contingentes aos sinais positivos do bebê. Analisar os diferentes contextos de desenvolvimento, a partir dos modelos expostos, é uma forma de compreender como tarefas de desenvolvimento universais (os cuidados parentais, por exemplo) são solucionadas de forma específica diante de condições culturais e ecológicas também específicas. Assim sendo, a construção do self é um processo complexo, gradual, dinâmico, que se mostra por diferentes facetas que se imbricam e se desenvolvem a partir de mútuas relações. Apesar de universal, move-se por trajetórias de desenvolvimento diversas em direção à conquista de uma maior ou menor interdependência ou independência. Apresenta, portanto, 
desenhos diversificados e particulares conforme a cultura e os contextos ecológicos e socioculturais nos quais se dá. Conhecer esse processo é um desafio que vem sendo enfrentado por diferentes autores da psicologia, particularmente, da psicologia do desenvolvimento.

\section{Metas de socialização da emoção e as necessidades de autonomia e relação}

A articulação teórica e empírica das metas de socialização de emoção com a tendência à valorização da autonomia e/ou relação interpessoal nas trajetórias de desenvolvimento nos parece um caminho rico e promissor para uma compreensão mais ampla dos processos ligados à parentalidade e ao desenvolvimento infantil. Ao ser assumido que as metas parentais de socialização da emoção, bem como a forma como pais e cuidadores pensam as emoções e lidam com elas têm implicações no desenvolvimento emocional desde os anos iniciais, faz-se necessário também considerar que suas tendências à valorização da autonomia e/ou relação impactam a forma e o conteúdo da vida emocional das crianças.

Nas sociedades ocidentais industrializadas, por exemplo, de acordo com Keller e Otto (2009), há valorização de tendências para uma maior independência e individualismo que incluem comportamentos que promovem autoexpressão e uma comunicação mais liberada e aberta da emoção. De modo diverso, alguns sistemas culturais são caracterizados como valorizando interações harmoniosas, cooperação e conformidade com as expectativas dos outros membros do grupo, como o asiático (Matsumoto et al., 2008b) e o encontrado na comunidade rural de Nso de Camarões (Keller \& Otto, 2009). Os autores relataram evidências de maior contenção nas expressões emocionais entre crianças que vivem nesses contextos (Matsumoto et al., 2008a), e de expectativas mais tardias por parte dos pais na manifestação de certas emoções por suas crianças (Keller \& Otto, 2009).

O que se pretende salientar nessa discussão não é o inquestionável papel da cultura nos processos sociais, na medida em que fornece orientações de nível macro para a sociedade, mas a imbricação de modelos de self (mais ou menos autônomos ou relacionais) com capacidades emocionais, nas trajetórias de desenvolvimento que vão sendo moldadas na ontogênese. Nesse sentido, em se tratando da infância, o foco está nas competências ontogenéticas da criança, assim como na forma como são interpretadas e valorizadas pelos cuidadores, e postas em prática nas interações sociais. Diferentemente dos estudos cujas reflexões estão voltadas para um plano mais amplo, das sociedades (individualistas $x$ coletivistas), e 
não dos indivíduos, o interesse aqui está centrado na noção de construção do self nos termos propostos por Kagitçibasi (2007) e Keller (2007).

A par da produção existente examinando a influência da cultura no processo de construção do self (vide Trommsdorff \& Cole, 2011, para outros estudos além dos mencionados), escassos parecem ser os estudos com o objetivo de examinar o que pensam e almejam os pais (e demais cuidadores) para seus filhos em termos emocionais de modo articulado com a priorização que estabelecem por um self mais autônomo ou mais relacional. Um dos identificados foi o de Keller e Otto (2009), voltado para a socialização da regulação emocional de bebês, que examinou as metas de socialização, crenças parentais e práticas, e as orientações em direção à autonomia e à relação em dois ambientes prototípicos (famílias ocidentais de classe médiaurbana, e famílias de um ambiente rural em sociedades não ocidentais). Além deste, podem ser destacados uma pesquisa realizada por Chan (2011) e um estudo brasileiro de Mendes e Cavalcante (2014).

Segundo Chan (2011), em Hong Kong, as mães chinesas valorizavam em seus filhos a construção de selves interdependentes (relacionais) e uma competência emocional também relacional. Embora tenham priorizado esta competência emocional relacional, também enfatizaram a competência emocional individualista como meta de desenvolvimento dos filhos. Nesse sentido, a competência emocional valorizada por mães com uma concepção de self independente inclui compreender as emoções, expressá-las de modo natural, especialmente as voltadas para o eu, e apresentar uma competência emocional independente ou individualista. De modo diverso, a noção de self interdependente, segundo a autora, enfatiza a importância de se aprender a regular as emoções, especialmente as centradas no eu, e incentiva as voltadas para o outro, priorizando uma competência emocional relacional.

No estudo brasileiro de Mendes e Cavalcante (2014), com interesse similar, foram entrevistadas mães e outros perfis de cuidadoras (avós, babás e educadoras de creche) do Rio de Janeiro. De acordo com os resultados apontados, o conjunto de participantes tendeu a valorizar tanto a autonomia quanto a interdependência nas crianças. Esse resultado foi confrontado com outras informações prestadas pelas participantes. Elas referiram ser a alegria a emoção que mais cedo uma criança apresenta (por volta dos três a quatro meses de idade), e a maior parte das mães acreditava que as crianças deviam aprender a controlar as emoções durante os três primeiros anos de vida (para as demais cuidadoras, $40 \%$ delas compartilhava essa ideia). Tanto esta resposta, quanto a fornecida para a razão pela qual consideravam importante uma criança sorrir, foram discutidas em termos do quanto poderiam indicar uma tendência para autonomia ou 
relação. Nesse estudo, quando indagadas se era importante uma criança sorrir, verificou-se que todas as participantes disseram que sim. Desse conjunto, $98 \%$ das mães e $87 \%$ das demais cuidadoras indicaram como razão principal para o sorriso, a importância de a criança manifestar suas emoções e sentimentos, em detrimento da disposição para ser simpática e agradável com as outras pessoas. Tais resultados, prosseguem as autoras no mesmo artigo, contrastam com os escores obtidos para autonomia e relação, e indicam a priorização de um self autônomo, com desejos e ações centradas no indivíduo, e não tanto nos aspectos voltados para a relação com o outro.

As diferenças culturais, como refletido nesses estudos, podem ter um impacto profundo nas expectativas e metas parentais e reações a expressões emocionais das crianças. Adicionalmente, parecem refletir outra dimensão nas metas de socialização, com foco nas necessidades humanas de autonomia e relação. Esforços são necessários para se examinar, de modo mais aprofundado, e com a articulação aqui proposta, a psicologia dos cuidadores quanto aos processos emocionais em desenvolvimento na infância e a valorização de selves mais autônomos ou mais interdependentes.

\section{Considerações finais}

Estudos sobre as metas parentais de socialização na infância além da contribuição que trazem para a temática da parentalidade podem apontar um caminho interessante quando se pretende compreender 0 processo pelo qual a criança desenvolve a capacidade de reconhecer, expressar e regular suas próprias emoções e lidar com as do outro. Dessa forma, as metas e expectativas parentais podem sinalizar o que querem os pais para os filhos em relação a aquisições que refletem o esperado preparo da criança para manejar formas emocionais de expressar o que ela sente e deseja, bem como o que concerne ao desenvolvimento dela como um indivíduo mais autônomo ou relacional. Com base nessa assunção, considera-se que as metas parentais se apresentam como tema relevante para investigações sobre a parentalidade em diferentes ambientes de socialização, particularmente no que concerne ao desenvolvimento emocional nos anos iniciais.

O que as crianças aprendem sobre as emoções costuma ser transmitido nas conversas com os pais e a partir de referências trazidas por seus comportamentos, que, por sua vez, foram guiados por suas concepções a respeito e por experiências passadas. Simultaneamente, mensagens são passadas à criança no que concerne ao modo como ela é vista, enquanto indivíduo e ser social, e do quanto deve buscar maior independência em relação a tradições, 
hierarquia social e ao grupo a que pertence. A forma como lida com as emoções parece imbricada ao modelo de self em desenvolvimento, mais autônomo ou não. Estes são domínios da socialização da emoção ainda pouco explorados quando se considera a sua importância para o desenvolvimento infantil.

O propósito desse trabalho foi o de trazer subsídios para um debate sobre as perspectivas de novas pesquisas acerca das metas parentais e modelos culturais, e seu impacto no desenvolvimento emocional e do self. Exemplos de pesquisas realizadas pretenderam indicar como as emoções podem ser interpretadas, valorizadas ou expressas de maneiras diversas em culturas diferentes. Além disso, destacaram a consideração de que as metas parentais podem ser orientandas por crenças diferentes sobre emoções e sobre as necessidades humanas de independência e relação, e ter sobre a criança, diferentes impactos.

Em síntese, este artigo pretendeu argumentar pela relevância de se estudar crenças e metas parentais ligadas a aspectos emocionais levando em conta o modelo de self que orienta pais e cuidadores na busca por um desenvolvimento para a criança mais marcado pela autonomia ou pela interdependência. Pretendeu, ainda, estimular novos estudos sobre as questões aqui tratadas, especialmente no que tange à necessária associação entre metas parentais de socialização da emoção e a construção de modelos do self, em contextos de desenvolvimento diversos.

\section{Referências}

Ayoub, C. C., Bartlett, J. D., \& Swartz, M. I. (2014). Parenting and Early Intervention: the impact on children's social and emotional skill development. In S. H. Landry \& C. L. Cooper (Eds.), Wellbeing in Children and Families: Wellbeing: $A$ Complete Reference Guide Vol I (pp. 179-210). NY: John Wiley $\&$ Sons, Inc.

Bailey, C. S., Denham, S. A., \& Curby, T. W. (2013). Questioning as a component of scaffolding in predicting emotion knowledge in preschoolers. Early Child Development and Care, 183, 265279. doi: $10.1080 / 03004430.2012 .671815$

Brownell, C. A., Svetlova, M., Anderson, R., Nichols, S. R., \& Drummond, J. (2013). Socialization of Early Prosocial Behavior: Parents' Talk About Emotions is Associated With Sharing and Helping in Toddlers. Infancy, 18(1), 91-119.

Camras, L. A., Chen, Y., Bakeman, R., Norris, K., \& Cain, T. R. (2006). Culture, Ethnicity, and Children's Facial Expressions: A Study of European American, Mainland Chinese, Chinese American, and Adopted Chinese Girls. Emotion, 6(1), 103-114. 
Chan, S. M. (2011). Mothers' construal of self and emotion socialisation goals. Early Child Development and Care, 181(5), 613-624.

Cheah, C. S. L., \& Chirkov, V. (2008). Parents' Personal and Cultural Beliefs Regarding Young Children: A Cross-Cultural Study of Aboriginal and Euro-Canadian Mothers. Journal of CrossCultural Psychology, 39(4), 402-423.

Denham, S., Caal, S., Bassett, H. H., Benga, O., \& Geangu, E. (2004). Listening to parents: cultural variations in the meaning of emotions and emotion socialization. Cognitie, Creier, Comportment, sept.-decem, 321-349.

Denham, S., \& Kochanoff, A. T. (2002). Parental Contributions to Preschoolers' Understanding of Emotion. In R. A. Farbes (Eds.), Emotions and the Family (pp. 311-343). NY: The Haworth Press, Inc.

Dix, T. (1991). The Affective Organization of Parenting: Adaptive and Maladaptative Processes. Psychological Bulletin, 110(1), 3-25.

Dunsmore, J. C., Her, P., Halberstadt, A. G., \& Perez-Rivera, M. B. (2009). Parents' beliefs about emotions and children's recognition of parents' emotions. Journal of Nonverbal Behavior, 33(2), 121-140.

Eisenberg, N., Spinrad, A., \& Cumberland, T. L. (1998). Parental Socialization of Emotion. Psychologycal Inquiry, 9(4), 241-273.

Ekman, P. (1999). Basic Emotions. Em T. Dalgleish and M. Power (Eds.). Handbook of Cognition and Emotion (pp. 45-60). Sussex, U.K.: John Wiley \& Sons, Ltd.

Ekman, P. (2003). Emotions revealed: recognizing faces and feelings to improve communication and emotional life. NY: Times Books.

Fine, S. E., Izard, C. E., \& Trentacosta, C. J. (2006). Emotion situation knowledge in elementary school: Models of longitudinal growth and preschool correlates. Social Development, 15(4), 730-751.

Harré, R. (1987). Enlarging the paradigm. New Ideas in Psychology, 5(1), 3-12.

Holodynski, M., \& Friedlmeier, W. (2010). Development of emotions and emotion regulation. NY: Springer.

Izard, C. E. (1977). Human Emotions. NY: Plenum Press.

Izard, C., Fine, S., Schultz, D., Mostow, A., Ackerman, B., Youngstrom,E. (2001). Emotion Knowledge as a Predictor of Social Behavior and Academic Competence in Children at Risk. Psychological Science, 12, 18-23.

Kagitçibasi. (2007). Family, self, and human development across cultures: Theory and applications. Mahwah, NJ: Lawrence Erlbaum Associates.

Kagitçibasi, C. (2012). Sociocultural Change and Integrative Syntheses in Human Development: Autonomous-Related Self 
and Social-Cognitive Competence. Child Development Perspectives, 6(1): 5-11.

Keller, H. (2002). Development as the interface between biology and culture: a conceptualization of early ontogenetic experience. In H. Keller, Y. H. Poortinga, \& A. Schölmerich (Eds.), Between culture and biology: perspectives on ontogenetic development (pp. 215-240), Cambridge: Cambridge University Press.

Keller, H. (2007). Cultures of Infancy. London: Lawrence Erlbaum Associates.

Keller, H. (2012). Autonomy and Relatedness Revisited: Cultural Manifestations of Universal Human Needs. Child Development Perspectives, 6(1), 12-18.

Keller, H., \& Chasiotis, A. (2007). Maternal investment. In C. A. Salmon \& T. K. Shackelford (Eds.), Family relationships: An evolutionary perspective (pp. 91-114). NY: Oxford University Press.

Keller, H., \& Greenfield, P. M. (2000). History and future of development in cross-cultural psychology. Journal of CrossCultural Psychology, 31, 52-62.

Keller, H., Lamm, B., Abels, M., Yovsi, R., Borke, J., Jensen, H., Chaudhary, N. (2006). Cultural Models, Socialization Goals, and Parenting Ethnotheories: A Multicultural Analysis. Journal of Cross-Cultural Psychology, 37(2), 155-172.

Keller, H., \& Otto, H. (2009). The cultural socialization of emotion regulation during infancy. Journal of Cross-Cultural Psychology, 40(6), 996-1011.

Kitayama, S., Mesquita, B., \& Karasawa, M. (2006). Cultural Affordances and Emotional Experience: Socially Engaging and Disengaging Emotions in Japan and the United States. Journal of Personality and Social Psychology, 91(5), 890-903.

Malti, T., Eisenberg, N., Kim H., \& Buchmann, M. (2013). Developmental Trajectories of Sympathy, Moral Emotion Attributions, and Moral Reasoning: The Role of Parental Support. Social Development, 22(4), 773-793. doi: $10.1111 /$ sode. 12031

Matsumoto, D., Yoo, S. H., \& Fontaine, J. (2008a). Mapping Expressive Differences Around the World: The Relationship Between Emotional Display Rules and Individualism Versus Collectivism. Journal of Cross-Cultural Psychology, 39(1), 5574.

Matsumoto, D., Yoo, S. H., Nakagawa, S., \& 37 Members of the Multinational Study of Cultural Display Rules (2008b). Culture, Emotion Regulation, and Adjustment. Journal of Personality and Social Psychology, 94(6), 925-937.

McElwain, N. L., Halberstadt, A. G., \& Volling, B. L. (2007). Motherand Father-Reported Reactions to Children's Negative 
Emotions: Relations to Young Children's Emotional Understanding and Friendship Quality. Child Development, 78(5), 1407-1425.

Mendes, D. M. L. F., \& Seidl-de-Moura, M. L. (2013). O Envelope Narrativo e o Desenvolvimento do Self: Um Estudo Longitudinal com Mães e Bebês nos Seis Primeiros Meses de Vida. Interação em Psicologia, 17(1), 37-46.

Mendes, D. M. L. F., \& Cavalcante, L. I. C. (2014). Modelos de self e expressão emocional em bebês: concepções de mães e outras cuidadoras. PSICO-PUCRS, 45(1), 120-129.

Mesquita, B. (2007). Emotions are culturally situated. Social Science Information 46, 410-415.

Meyer, S., Raikes, H. A., Virmani, E. A., Waters, S., \& Thompson, R. A. (2014). Parent emotion representations and the socialization of emotion regulation in the family. International Journal of Behavioral Development, 38(2), 164-173.

Nelson, N. L., \& Russell, J. A. (2013). Universality Revisited. Emotion Review, 5(1), 8-15.

Russell, J. A. (1991). Culture and the categorization of emotions. Psychological Bulletin, 110, 426-450.

Schröder, L., Keller, H., Kärtner, J., Kleis, A., Abels, M., \& Yovsi, R. D. (2013). Early Reminiscing in Cultural Contexts: Cultural Models, Maternal Reminiscing Styles, and Children's Memories. Journal of Cognition and Development, 14(1), 10-34.

Seidl-de-Moura, M. L., Carvalho, R. V. de, \& Vieira, M. L. (2013). Brazilian Mothers' Cultural Models: Socialization for Autonomy and Relatedness. In M. L. Seidl-de-Moura (Ed.), Parenting in South American and African Contexts (pp. 1-15). InTech - Open Access Publisher. doi: 10.5772/57083.

Seidl-de-Moura, M. L., \& Mendes, D. M. L. F. (2012). Human Development: The role of biology and culture. In M. L. Seidl-deMoura (Ed.), Human Development - Different Perspectives ( $p p$. 3-18). InTech - Open Access Publisher. doi: 10.5772/36474.

Seidl-de-Moura, M. L., Targino, T., Nahum, K., Cruz, E. M., Amaral, G., \& De Marca, R. (2009). Parenting cultural models of a group of mothers from Rio de Janeiro, Brazil. Spanish Journal of Psychology, 12(2), 506-517.

Trommsdorff, G., \& Cole, P. M. (2011). Emotion, Self-Regulation, and Social Behavior in Cultural Contexts. In X. Chen \& K. H. Rubin (Eds.), Socioemotional Development in Cultural Context (pp. 131-163). NY: The Guilford Press.

Vieira, M. L., Seidl-de-Moura, M. L., Macarini, S. M., Martins, G. D. F., Lordelo, E. da R., Tokumaru, R. S., \& Oliva, A. D. (2010). Autonomy and Interdependence: Beliefs of Brazilian Mothers from State Capitals and Small Towns. The Spanish Journal of Psychology, 13(2), 818-826. 
Wong, M. S., Diener, M. L., \& Isabella, R. A. (2008). Parents' emotion related beliefs and behaviors and child grade: Associations with children's perceptions of peer competence. Journal of Applied Developmental Psychology, 29, 175- 186.

\section{Endereço para correspondência \\ Deise Maria Leal Fernandes Mendes}

Universidade do Estado do Rio de Janeiro

Instituto de Psicologia

Rua São Francisco Xavier, 524, bloco F, $10^{\circ}$ andar, Maracanã, CEP 20550-013, Rio de Janeiro - RJ, Brasil

Endereço eletrônico: deisefmendes@gmail.com

Luciana Fontes Pessôa

Pontifícia Universidade Católica do Rio de Janeiro

Departamento de Psicologia

Rua Marquês de São Vicente, 224, Cardeal Leme, sala 201, Gávea, CEP.22451-900,

Rio de Janeiro - RJ, Brasil

Endereço eletrônico: pessoalf@gmail.com

Lilia I êda Chaves Cavalcante

Universidade Federal do Pará

Instituto de Ciências Sociais Aplicadas

Avenida Augusto Correa, 01. Guamá, CEP 66033-000, Belém - PA, Brasil

Endereço eletrônico: liliaccavalcante@gmail.com

Recebido em: 01/08/2015

Aceito para publicação em: 14/04/2016

\section{Notas}

* Doutora em Psicologia Social pela UERJ.

** Doutora em Psicologia Social pela UERJ .

*** Doutora em Teoria e Pesquisa do Comportamento pela UFPA. 